\title{
The Use of Deliberative Democracy in Public Policy Making Process
}

\author{
Nabaz Nawzad Abdullah \\ School of Law, Government and International Studies, Universiti Utara Malaysia \\ 11J002, DPP Maybank, UUM, 06010 Sintok, Kedah, Malaysia \\ Tel: +60 (10) 5291413 Email: nabaz4u@yahoo.com \\ Mohd Fitri Abdul Rahman Ph.D \\ School of Law, Government and International Studies, Universiti Utara Malaysia \\ 11J002, DPP Maybank, UUM, 06010 Sintok, Kedah, Malaysia \\ Tel: +60 (17) 4992982 E-mail: mohdfitri@uum.edu.my
}

\begin{abstract}
This paper intends to highlight the intensity of the use of deliberative democracy in the policy making process. It assists policy makers to understand the significance of deliberative democracy and the preliminary conditions to conduct effective and successful deliberation for the purpose of producing best quality decisions. This paper stressed the relationship between deliberation and citizen's satisfaction of government decisions. It indicated that deliberative democracy helps citizens to directly influence on the quality of the decision and better represent their preferences by proposing their agenda and views on policy alternatives and issues. Deliberative democracy is a technique that stabilizes citizens' interests by diminishing domination, despotism, and better assessing public choices. This paper found that deliberation legitimizes government decisions and maximizes the outcome of the policies. This article defined several advantages of deliberative democracy in the public policy making process which pursues equality, mutual interest; reason based discussion, public goods, the decision focused and agreement on disputed preferences. It also concluded that deliberative democracy facilitates free and fair participation and creating opportunity for discussion and information sharing between participants prior to the implementation process of government policies.
\end{abstract}

Keywords: Public deliberation, deliberative democracy, public participation, decision making, public policy

\section{Introduction}

Many scholars have so far studied public deliberation, especially political philosophers, but little consideration has given to public deliberation in real life situation in respect to the policy making process (Stie, 2011). They mainly treated public deliberation as a form of political democracy, and neglected the prominence of deliberation in public administration and decision making process. The fact is deliberation can even occur in other forms of government, such as authoritarian regimes; but not as effective as democratic governments (Parkinson \& Mansbridge, 2012). Hence, this paper found it very significant to determine how public deliberation influences policy decisions related to real life situation. We explore a mechanism to conduct effective deliberation program which may help democratic institutions to further improve participatory mechanisms in order to track better policy decision.

Public deliberation in general form is a multi-dimensional theory which has been studied in various types of research, including political philosophy (Cohen, 1997; Gutmann \& Thampson, 1996), communication (Carcasson, Black, Sink, 2010; Pearce \& Littlejohn, 1997; Gastil, 1993), public opinion (Gastil, 2008; Page, 1996), citizens' juries (Crosby,1995) and several others. It is an important motive of democratic governance in which urges to involve citizens and stakeholders in the governing process. Public deliberation is a citizen centric process that maintains the interest of the public and treats them as a nub of government decisions.

Public deliberation in public policy refers to the discussion between citizens and government officials to collectively conclude policy decision. So, it is realized by scholars as the capacity of community members to get into the meaningful dialogue based on reasons and come out with judgments in order to solve public issues concerning by public (Roberts, 2004, p. 340).

Public deliberation in citizen's perspective is the process of making difficult choices among variety of alternatives that can best serve community needs and preferences. They also described public deliberation as a method of discussion and binding individual groups together where they challenge to input their agenda in the 
policy (Gentry et al, 2012).

If in the past, voting was the only way to pursue democracy, recently deliberation is more important to evaluate democracy and public participation. It is been emphasized in the work of Chang (2012) that to promote public goods, deliberation should be used to connect the process of policy decision making along with reasoned based discussion where members of society come together to make certain decisions. For him, it's a transformational process of democracy in the modern age were reasoned based discussion replaced indirect democracy. More precisely, democracy is not merely talk-centric rather than vote centric. In this study, we emphasize on the significance of public deliberation in the public policy making process. We aim to identify the pre-required conditions to underpin successful and effective deliberation. As the study highlighted the situation where effective deliberation could be in place; then, the study will identify the outcomes that could achieve from the process.

\section{Defining Public Deliberation}

Public deliberation is defined in different ways and yet there is no standard definition. Therefore, most definitions focusing on reasoned based discussion among people over policy issues (Mathews, 1994, p. 110; Burkhalter, Gastil, \& Kelshaw; 2002; Gastil, Black, \& Lawra, 2008).

Mathews (1994) defined deliberation as a careful weighing of different alternatives to act thoroughly along with others opinion. Not so different from Mathews, Burkhalter, Gastil, and Kelshaw (2002) defined public deliberation as a combination of democratic process known as egalitarian, where citizens are given an equal chance to speak up their concern and demands through dialogue and tentative discussion with delicate analyses of the problems.

Another definition is given by Gastil, Black, and Lawra (2008) which public deliberation for them means the process of getting people together to examine problems carefully and find out solutions for the existed problem based on the reasons where differences and views highly respected. Thus, by combining the aforementioned definitions, public deliberation could be defined as the form of democratic decision making which assists people to propose relevant alternatives and carefully discussing them through methods of deliberation afore reaching to the final decision.

\section{Deliberative Democracy Theory}

The history of democracy dates back to the Romans and Athens, but the democratic forms have changed gradually and new theories derived from the mother democracy such as deliberative democracy. Actually, traditional form of democracy mainly focuses on voting process when it comes to the issue of decision making and citizens' participation in policy formulation. In deliberation, Cohen (1989) and Hebermas (1984) clarified that the traditional theory of deliberation was based on equality, equity, and public goods; but, the modern theorists of deliberation more emphasize on the significance of deliberation on social aspects (Gastil, Black, \& Lawra, 2008). In this respect, deliberative democracy involves citizens and stakeholders in the decision process in more broaden way.

Elster (1998) describes the notion of deliberative democracy as the process of making collective decisions through the engagement of all stakeholders by offering them a reason based discussion. Cohen and Fung (2004) similarly explained the concept as the relationship between citizens collective judgment with public policy decision in which derived from deliberation process. Chambers (2003) emphasize that in deliberative democracy, citizens engaging in formulating policies from all stages of policy making by offering various methods to overcome weak citizenship and combining each participant views to discover the best solution to policy issues rather than just giving citizens a chance to vote without participation.

Deliberation is democracy, but not every type of democracy is deliberation. Habermas (1989) argues that democracy could not only become deliberative by transcending individual interests, but it could be deliberative when those who are affected by decisions combining their interests to generate common ground. In the other words, those who are affected by decisions and their representatives should directly engage in the process. Accordingly, decisions could only be democratically legitimate when it is from the ground where citizens are submissive to as it ensures that stakeholder options are fed into the process of policy making Therefore, concerns that feed into the process should be derived from relevant information and data, not randomly everyone's agenda to be placed in the decision (de la Porte \& Nanz, 2004).

Cohen (1997) stated that deliberative forms the characteristics of citizens and preserving their interests through their contribution in the process of making the outset of the common good. Rawls (1993) on the other hand, concentrates on the approach of equal citizenship in his literature and correlated to the public goods. However, Habermas (1984) concern about entails of public deliberation and argues that there should be no limitation for 
citizen participation and public process should bounded by moral consideration. Habermas also rejects any exclusion and domination. He maintains that in the absence of equal participation, no agreement could be achieved. Cohen (1989) and Rawl (1993) claim that decisions made in public through citizen participation will promote justice and equity, but Habermas (1984) claims that communicative rationality and legitimacy are core values of deliberation. This point supported by Elster (1995) as he believes the theory of democratic deliberation influence on the legitimacy of the policy choices and contributes in providing relevant information for citizens to engage in policy formulation. He also maintains the use of deliberation for maximizing the equity of the policy choices and citizens' commitment and better policy outcome could be obtained (Elster, 1995). Deliberation also deals with the stability of public interest by diminishing domination and better assessing people's preference (Dryzek \& Christian, 2003).

\section{Methods of Deliberation}

The process of deliberation could be in place through the use of different methods, including public discussion, public debate (de la Porte \& Nanz, 2004) which seen to be significant to form public choices and alternatives based on reason-centric analysis, public meeting, citizens panel, citizens' conference, which supposedly to be funded by the NGOs and government or private foundation to help citizens to engage in the decision making process for the sake of maximizing public goods (Chambers, 2003, p.316). Chamber also highlights that the main objective of deliberative is to generate legitimate decision through public participation, urging citizens commitment, cooperation in the decision process, refining mutual understanding between individuals, avoidance of any methods of exclusion and promotes the quality of decisions through discussions (Chambers, 2003, p.317). In democratic deliberation, every citizen that somehow affected by the decision, is expected to engage in policy formulation. Furthermore, public participation in deliberative democracy theory is not only requires citizens to physically engage in policy formulation as discussed by Goodin and Niemeyer (2003), but there are several ways that citizens can find opportunity to involve. For instance, Niemeyer and Dryzek (2007) produced the model which known as "intersubjective rationality" in which they use tools of communication to lead equality, mutual interest, reason based discussion, public goods, the decision focused and agreement on disputed preferences.

Deliberative forum and venue could also be used to assist people in the deliberation process. In deliberation venue, citizens bring up common issues and discuss policy choices with other members of the community in order to conclude with certain decisions accepted by a majority of the participants. It is also a mean to encourage people to carefully express their views and adopt possible solutions to existing problems. Lastly, Goodin (2000) emphasized that participants can even deliberate with themselves and it is known as internal deliberation. Internal deliberation helps individuals to come up with a new idea through interpersonal communication and then share it with a wider group.

\section{The Preliminary Elements of Effective Deliberation}

The elements of deliberative democracy do not solely function effectively, but they needs to adhere to some preliminary conditions. Jonga (2012, p. 130) illustrated that deliberative democracy theory functions under a special environment where equality, transparency, integrity, communication and participation are rationally goes together. Such environment shifts individual preference towards common goods without conflicting others interest. The following elements are significant to be considered before getting into the deliberation; otherwise, the process may not meet it is objectives.

\section{Equal Opportunity}

Equality is a pre-condition to successful deliberation (Jonga, 2012; Druckman \& Nelson, 2003; Nabatchi, 2010; Gastil, 1993; Burkhalter, Gastil \& Kelshaw, 2002; Gastil, Black, \& Lawra, 2008). Jonga (2012) highlights the most important determination of well-functioned deliberative which is the avoidance of individual domination and giving participants an equal chance to share their preferences. Druckman and Nelson (2003) emphasize that deliberation protects subordinates or ordinary citizens from the domination of elites which they normally have major impacts on the decision, but this process is a clear cut of democracy and limits their power to manipulate discussions.

Gastile (1993) believes that stakeholders in public policy deliberation should be given an equal chance to express their concern and propose their alternatives (Gastil, 1993). It might be argued that it is difficult for everyone to speak up in a kind of deliberation where many participants are engaged. However, when a chance is given to someone to speak up and other participant is neglected, then it produces moral conflicts and it may even illegitimate policy decision where not everyone could have an opportunity to input their agenda or to propose 
their alternatives. However, it is possible to overcome this issue. When participants need additional time to speak and there is not enough time to allow them to speak up, then alternative solution should be in place. For that Burkhalter, Gastil and Kelshaw (2002) proposed that "equal speaking time" principle should be practiced to determine each individual's speaking time. Equal chance here does not mean everybody obliged to speak their mind, but they should be left free to speak or not. Therefore, when they decide to speak, they shouldn't be stopped or limited in giving their views, but they have to be heard and respected. Also, speakers should use a language where every participant able to understand the problems at stake.

\section{Respect to Participants}

Deliberative democracy considers ethical problems and respects the diversity of interests and views; otherwise, it could be so hard for individual participants find themselves in the discussions where conflict arises due to the ethical issues. Participants should be treated sincerely with honor and pride. They should not be interrupted when they want to deliver their views (Gastil, Black, \& Lawra, 2008). In this manner, the voice of all participants needs to be heard and equal opportunities to be given to them.

\section{Availability of Information to Participants}

In democratic deliberation, information should be available for each participant and it is morally justified for stakeholders to request such information as it is a moral obligation for those who are holding the information to hand over to individual participants (Gastil, 1993). It is difficult to expect people to govern themselves without proper knowledge of the process and data that needed to engage in decisions. In this respect, transparency and the flow of information should be in place. Transparency in ways that stakeholders including citizens, NGOs, local government have access to all relevant information needed in the process (de la Porte \& Nanz, 2004). Therefore, availability of information is not solely empowers participants to deliberate policy decisions, but they need to be educated and comprehend (Gawthrop, 1998; Nabatchi, 2010, p.381) the nature of the process in advance. Gouran and Hirokawa (1996) arguing that a more effective deliberative discussion is the one that integrates with the adequacy, reliability of information and knowledge based. Deliberation can not produce proper decision unless there is accurate information in which individual participants have access to it. Information as Hebermas (1984) emphasized could be in the forms of statistic, survey, or objective measurements that goes beyond individual biases.

\section{Participate in Coordination with Policy Makers}

In public policy making decision may be incredibly effective if it happens in coordination with government officials since officials can better understand the issues when they are facing their citizens and listening to their concerns other than getting information in the second sources (Gastil, Black, \& Lawra, 2008). However, deliberation is not all about alternatives and solutions, but it also requires the way that people deliberating and communicating. The significances of deliberation could be extended when officials and citizens together deliberate policies. As a duty of policy makers, citizens need to be empowered to manage themselves in developing policy alternatives and furnishing policy gaps (Wildavsky, 1979). This produces a healthy tie between government and the wider community to better understand each other and strive to obtain mutual interests. Besides, officials may get benefits from the citizens' experience, as citizens learn policy making process much deeper and restore the faith towards government (Gastil, Black, \& Lawra, 2008). Respectively, the government officials should engage in analyzing information that assists policy makers to mobilize public support to the policy decision (Bessette, 1994).

\section{Diversity of Views}

The other precondition (Fishkin, 1991; Dahl, 1989) of deliberation is the availability of diverse views, interest, alternatives, and solutions. Deliberation should promote evaluation criteria where the ethics of discussion are considered. In the absence of evaluation criteria and conflicting issues in relation to moral values which make it difficult for participants to produce effective decision. Also, participants need to prioritize their needs and offer a set of alternative and solutions to work on. Without offering alternatives and taking everybody's interest into account, deliberation may not happen. Then, a range of possible solution should be used to deal with problems. Also, in deliberation, tradeoffs should happen among conflicted alternatives (Munno \& Nabatchi, 2014).

\section{Preserving Participants Interest}

In deliberation, it is always expected that participants pursuing their interests in the deliberation process, but it is treated as a way to understand stakeholder concerns. Therefore, to deal with that, their interests should be considered (Nabatchi, 2010) and an equal opportunity to be given to them in order to defend their interests. This 
will also encourage them to further participate in deliberation process even more effectively. Therefore, when participants feeling their interests deserted, they will be disappointed to participate in the future activities as their values are not respected. Thus, it is imperative to carefully listen to every participant, especially when it is about the wider community (de la Porte \& Nanz, 2004). However, the inclusion of stakeholders and considering their views is not the only way to peruse healthy deliberation, but individual participants should come out with innovative solutions that can target the interest of wider community rather than alternatives that only elites or certain people can get benefits.

\section{Learning and Responsiveness}

Learning and responsiveness are two normative determinants of effective deliberation (Nabatchi, 2010). Learning referred to the experiences and empowering citizens' skills, which promotes the quality of regulatory alternatives. More preciously, it means that policy makers and participants should learn from past mistakes and success to enforce better policy choices. The past knowledge can help them to better understand the process and get rid of misleading agenda. Consequently, it will ensure the quality decision to be made which is more possible to success (de la Porte \& Nanz, 2004).

Responsiveness means that policy makers from government departments respond to the concern of local communities and act accordingly. Therefore, the final decision and discussion is among policy makers (de la Porte \& Nanz, 2004). Responsiveness is the extended of voices that has been heard by policy makers in the decision making process. Citizens when engaging in democratic deliberation, expecting their voices to be heard not just symbolically participate in the process in order policy makers justify their decisions. Therefore, it is expected from government to carefully respond to citizen concerns and formulate policies, especially those that have direct impacts (de la Porte \& Nanz, 2004).

\section{Public Deliberation Predicament}

The theorists of deliberative democracy, raises one important question which is egotism of the individuals participants in which effects on their preferences and judgments; however, Mansbridge et al (2010) argue that self-interest should also be included and necessary in deliberation as defined by the aggregative models. Their justification for that is motivating individuals to participate and creates the sense of community in which public goods could be achieved thoroughly. Further explanation set by Mansbridge et al (2010) which believe when citizens engage in policy decisions, they know the impacts of policy on their livelihood and establishing best mechanism to obtain better policy outcome.

Fishkin argues that public deliberation could be used as a method to overcome issues of representation. However, he contended that people may not be well represented as representatives have some interest in the process and somehow directed by elites; therefore, public deliberation can possibly resolve this issue by getting stakeholders into the process (Choi, 2014). For instance, if only representative of communities engages in budget discussions, their representation may be surpassed by their self-interest. So, they may emphasize more to their interests and elites that direct them and propose projects that better service them instead of the wider community.

In the public deliberation process, participants usually proposed variation of alternatives and set of solutions. So, it's possible when conflicts over policy alternatives and solution arise among participants. Accordingly, evaluation criteria should be applied to determine the effects of each solution as well as alternatives that proposed during the deliberation process. Obviously, the interests and objectives of the participants are varied; accordingly, they propose different agenda. In this case as discussed by Mathews (1994), value trade-offs between proposed solutions and alternatives should be carefully analyzed by stakeholders as a deliberation process is about making difficult choices among inconsistent options.

\section{The Value of Deliberate on Public Policy Process}

Several scholars like Mill and Rousseau emphasized on the significance of deliberation in the public policy process. They portrayed deliberation as the method to reach collective decisions which for Mill known as the common good and the general will for Rousseau (Patmen, 1970). Both theorists are consent in the point where deliberation maximizes the sense of belonging among citizens that can ensure more commitment.

Deliberation has both direct and indirect impacts on participants' skills. It could directly underpin their skills and knowledge and indirectly motivates participants' identities and strengthen the sense of political efficiency, which results in promoting common goods (Burkhalter, Gastil, and Kelshaw, 2002). Deliberation is highly appreciated in the sense that it empowers citizens and cultivates them with knowledge in reference to the complexity of the process (Munno \& Nabatchi, 2014).

According to the National Consumer Council (2008) deliberation helps policy makers to offer better policy, 
provide better services and enhance social ties as well as promote democracy. Deliberation has previously applied in several countries including UK and Brazil; the research found that public participation through deliberation promotes the quality of the decision (Munno and Nabatchi, 2014) and enriches policy makers experience in problem solving and policy formulation process.

Several other advantages could be generated from deliberation as defined by Game theory of deliberative democracy includes the facilitating of free and fair participation and creating opportunity for discussion and information sharing between participants prior to the voting process on certain policies. As explained by Linda and Meirowitz (2009), in this approach of deliberative democracy there are three main stages that participants given opportunity to share what else they have on certain policy process. The first stage is available choices that participants can deliberate and giving their opinion and the effects of their participation to realize the extent of hearing their concerns by policy makers. The second stage helps to evaluate the information that participants poses and the way to interact with each other. Lastly, participants realize the essence of their participation in the decision process and the output of their participation on selecting priorities. Consequently, an inclusive decision could be formulated that better goes along public needs (Parkinson \& Mansbridge, 2012).

\section{Discussion}

Deliberation is different from other forms of participation as participants given a chance to discuss problems prior to the decisions. Deliberation helps to directly feeding citizens into the process to compete their interests and making better policy choices. This study highlighted that public deliberation can positively generate quality decision and citizens can find themselves in the governing process if it follows certain conditions. In this regard, policy makers have to carefully listen to individual participants and their views on the issues. Individuals participating policy discussions need to know why they are participating, comprehend the discussion, and understand the decision making process. Participants also need to obtain all information about the discussion and the reports that would be preceded after the completion of the process. So, the outcome of participation should be clear to all stakeholders and the way their views input in the policy decision. In all stages of policy making from agenda setting to evaluation, participants must be kept informed. They also need to be informed to what extend their views fed into the final decision.

In well functioned deliberation, policy makers taking participant views sincerely. Also, the right individuals need to take part in the policy discussion and debates with clear needs and intentions. In this research, we noted that diversification of participants in terms of demography and views provides a better chance for policy makers to make proper decisions by using a different agenda from people with different background and interest. Diversification is very important in the decision making process, especially involving marginalized groups who were far neglected and feel ignored by the government. Marginalized groups could be people with special needs, poor, elder people, and people in the remote areas. The core significance of deliberation is engaging all kinds of groups which even increase their sense of citizenship. It legitimizes the decision, and more importantly quality decision could be made with inclusion of all sectors of society regardless their color, race, economic background and others. The main objective of deliberative democracy is to satisfy public needs and reaching to the collective decision and that could only be achieved if the process follows effective deliberation principles. Lastly, this study found that the well-functioned democratic deliberation generates the following outcomes:

1- Citizens can better understand priorities and community values

2- Deliberative democracy increases accountability of policy makers towards their citizens.

3- Policy makers can achieve better understanding of public concerns and many alternatives could be discussed by citizens.

4- Policy makers can benefit from their comments and suggestion to further promote public services according to the inputs received from stakeholders.

5- Public deliberation empowers citizens and cultivate them with new experience, new information, and knowledge concerning the decision making process.

6- Public deliberation encourages the flow of information among participants, which empowers citizens to make prioritize better choices.

7- Public deliberation increases citizens' commitment towards government decision.

8- Public deliberation legitimizes policy decisions.

9- It encourages active citizenship and promotes citizens' confidence toward policy makers.

10- Citizens better understand the status of their government and the extend of democracy, openness and accountability of their governments.

11- Deliberation enhances relationship between government, citizens that generate partnership the sense of belonging between citizens and government in one hand, and social groups on the other hand. 
12- Participants may create better ties among themselves and cooperate in the future works.

13- Deliberative can become a platform to promote mutual understanding

14- Public deliberation increases respect between community members and decision makers.

15- Citizens can deliver better services

\section{Conclusion}

Public deliberation is a very effective method to promote good governance practices. In the democratic world, there are many forms of governing practice, but when it comes to the decision making process, deliberation is one of them. Public deliberation in public policy making is a bridge between citizens and policy makers that make that helps them to understand each other and collectively work to fulfill public interest. Deliberation as a theory practiced long times ago, but deliberative democracy which is the most common form of deliberation is just recent. Deliberative democracy helps citizens to transfer their agenda into the public process where stakeholders all together form a collective decision. The collective decision is normally legitimized by the mass population. The theory could be applied on different sectors of government, especially on service issues were directly influence on the quality of public life. Since citizens expecting best services from government, it is important to understand the nature of the services and projects that citizens need the most. In this sense, deliberation could be used to define their needs and discussing all possible alternatives. Deliberation to meet public demands requires preliminary environments, including the availability of information, respect, mutual interest, pluralism, diversity of views and interests, open and honest discussion, equal opportunity to participate, equal opportunity to speak up, learning, empowerment and responsiveness.

This study concluded that the process of deliberation not always goes smoothly, but due to the diversity of views and population, conflicts may arise at any moment. However, conflicts could be resolved when there is a strong sense of belonging among participants who sincerely participated to maximize common goods. When deliberations abide by aforementioned conditions, effective and well-functioned public deliberation could be guaranteed. Accordingly, policy makers can make better choices among conflicted alternatives through knowledge, experience, and information received from individual participants. Such decision promotes citizens' commitment towards officials and decision will be respected by the wider community with inclusion of every single stakeholder. Lastly, we should bear in mind that democratic deliberation is a voluntary process. Clearly, every stakeholder should be invited and to be fortified to participate, but it is not a compulsory process to force them to attend.

\section{Directions for future studies}

It would be imperative if researchers conduct further studies on the use of public deliberation specifically in the capital budgeting process as a modern form of democracy that globally applied by many municipalities. However, not so much attention is given to the relationship of democratic deliberation in public budgeting process that citizens may see it as an effective participatory mechanism to induce public service delivery.

\section{References}

Bessette, J. (1994). The Mild Voice of Reason: Deliberative Democracy and American National Government. Chicago IL: University of Chicago Press.

Burkhalter, S., Gastil, J. \& Kelshaw, T. (2002). Conceptual definition and theoretical model of public deliberation in small face to face groups. Communication Theory, 12 (4), 398-422.

Carcasson, M., Black, L. W., \& Sink, E. S. (2010). Communication Studies and Deliberative Democracy: Current Contributions and Future Possibilities. Journal of Public Deliberation, 6 (1), 1-42.

Chang, D. (2012). Deliberative democracy: public reason and the common good. Seoul: Parkyoungsa.

Chmbers, S. (2003). Deliberative Democratic Theory. Annual Review of Political Science, No. (6): 307-326.

Choi, I. (2014). What explains the success of participatory budgeting? Evidence from Seoul autonomous districts. Journal of Public Deliberation, 10 (2), 12.10.2014

Cohen, J. (1989). Deliberative democracy and democratic legitimacy. (Hamlin, A. and Pettit, P. eds.), The Good Polity. Oxford: Blackwell.

Cohen, J. (1997). Deliberation and democratic legitimacy in Bohman and Rehg (1997). pp. 67-91.

Cohen, J., \& Fung, A. (2004). Radical democracy. Swiss Journal of Political Science, 10, 23-34.

Crosby, N. (1995). Citizen juries: One solution for difficult environmental questions. In O. Renn, T. Webler, P. Wiedemann (Eds.), Fairness and competence in citizen participation: Evaluating models for environmental discourse (pp.157-174). Boston: Kluwer 
Dahl, R. A. (1989). Democracy and its critics. New Haven, CT: Yale University Press.

de la Porte, C. \& Nanz,P. (2004). The OMC- a deliberative-democratic mode of governance? The cases of employment and pensions. Journal of European Public Policy, 11 (2), 267-288. DOI: $10.1080 / 1350176042000194430$.

Druckman J.N. \& Nelson K. R. (2003). Framing and deliberation: how citizens' conversations limit elite influence. American Journal of Political Science, 47, 729-45.

Dryzek, J. S., \& Christian L. (2003). Social choice theory and deliberative democracy: A Reconciliation. British Journal of Political Science, 33 (1), 1-28.

Elster, J. (1995). Strategic uses of argument in barriers to conflict resolution. New York: Norton.

Elster, J. (1998). Introduction. In J. Elster (Ed.), Deliberative democracy (pp. 1-18). Cambridge, MA: Cambridge University Press.

Fishkin, J. S. (1991). Democracy and deliberation: new direction for democratic reform. New Haven, CT: Yale University Press.

Gastil, J. (1993). Democracy in small groups: participation, decision making, and communication. Philadelphia: New Society.

Gastil, J. (2008). Political Communication and Deliberation. Thousand Oaks, CA: Sage.

Gastil, J., Black, \& Lawra. W. (2008). Public deliberation as the organizing principle of political communication research. Journal of Public Deliberation, 4 (1). Retrieved from http://www.publicdeliberation.net/jpd/vol4/iss1/art3

Gawthrop, L. C. (1998). The human side of public administration. PS: Political Science and Politics, $31,763-$ 769.

Gentry et al. (2012). Financial fittest: Its priceless public policy deliberation guide. Alexandria, VA: American Association of Family Consumer Sciences.

Goodin, R. E. \& Niemeyer, S. (2003). When does deliberation begin? Internal reflection versus public discussion in deliberative democracy. Political Studies, 51(4).

Goodin, R. E. (2000). The constitutional of society. Berkeley: University of California Press.

Gouran, D. S. and Hirokawa, R. Y. (1996). Functional theory and communication in decision making and problem solving groups: An expanded view. In R. Y. Hirokawa and M.S. POOLE (eds.), Communication and group decision making ( $2^{\text {nd }}$ edition, p. 55-80). Thousand Oaks, CA: Sage.

Habermas, J. (1984). Theory of communicative action. Boston: Beacon Press.

Habermas, J. (1989). The structural transformation of the public sphere. Cambridge: MIT Press

Jonga (2012). Prioritizing political banditry than good governance: Rethinking urban governance in Zimbabwe. International Journal of Humanities and Social Science, 2 (24), 117-135.

Linda, D. \& Meirowitz, A. (2009). Game Theory, Information, and Deliberative Democracy. American Journal of Political Since Association, 53 (2), 427-444.

Mansbridge, J. (2010). Deliberative polling as the gold standard. The Good Society, 19 (1), 55-62.

Mathews, D. (1994). Politics for people: Finding a responsible public voice. Chicago: University of Illinois Press.

Munno, G \& Nabatchi, T. (2014). Public Deliberation and Co-Production in the Political and Electoral Arena: A Citizens' Jury Approach. Journal of Public Deliberation: 10 (2), 1-31. Retrieved from http://www.publicdeliberation.net/jpd/vol10/iss2/art1

Nabatchi, T. (2010). Addressing the citizenship and democratic deficits: the potential of deliberative democracy for public administration. The American Review of Public Administration. 40 (4), 376-399, DOI: $10.1177 / 0275074009356467$

National Consumer Council(2008). Deliberative public engagement: Nine principles. Retrieved from http://www.involve.org.uk/wp-content/uploads/2011/03/Deliberative-public-engagement-nineprinciples.pdf.

Page, B. I. (1996). Who deliberate? Mass media in modern democracy. Chicago: University of Chicago Press.

Parkinson, J., \& Mansbridge, J. (2012). Deliberative System: Deliberative democracy at the large scale. Second edition. UK: Cambridge University Press.

Pearce, W. B., \& Littlejohn, S. (1997). Moral Conflict: When social worlds collide. Thousand Oaks, CA: Sage.

Rawls, J. (1993). Political Liberalism. New York: Columbia University Press.

Roberts, N. (2004). Public deliberation in an age of direct citizen participation. American Review of Public Administration, 34, (4), 315-353, DOI: 10.1177/0275074004269288.

Stie, A. E. (2008). Assessing democratic legitimacy from a deliberative perspective. (No. 6). Oslo: Centre for European Studies 
Wildavsky, A. (1979). Speaking truth to power: The art and craft of policy analysis. New Brunswick, NJ: Transaction.

\section{Biography}

Nabaz Nawzad Abudllah, holds a Bachelor degree in Politics \& International Relations from University of Kurdistan Hewlêr (UKH) and Master Degree in Public Management from Northern University of Malaysia (UUM). He is currently a PhD. Student at the School of Government, Collage of Law, Government and International Studies, Universiti Utara Malaysia. He writes his thesis about "The Impacts of Public Participation in Public Budgeting Process of Kurdistan.”

Moh Fitri Abd Rahman, holds a PhD. in Comparative Politics from Northern University of Malaysia. He is a senior lecturer at the Department of Public Management, Collage of Law, Government and International Studies, Universiti Utara Malaysia. 
The IISTE is a pioneer in the Open-Access hosting service and academic event management. The aim of the firm is Accelerating Global Knowledge Sharing.

More information about the firm can be found on the homepage:

http://www.iiste.org

\section{CALL FOR JOURNAL PAPERS}

There are more than 30 peer-reviewed academic journals hosted under the hosting platform.

Prospective authors of journals can find the submission instruction on the following page: http://www.iiste.org/journals/ All the journals articles are available online to the readers all over the world without financial, legal, or technical barriers other than those inseparable from gaining access to the internet itself. Paper version of the journals is also available upon request of readers and authors.

\section{MORE RESOURCES}

Book publication information: http://www.iiste.org/book/

Academic conference: http://www.iiste.org/conference/upcoming-conferences-call-for-paper/

\section{IISTE Knowledge Sharing Partners}

EBSCO, Index Copernicus, Ulrich's Periodicals Directory, JournalTOCS, PKP Open Archives Harvester, Bielefeld Academic Search Engine, Elektronische Zeitschriftenbibliothek EZB, Open J-Gate, OCLC WorldCat, Universe Digtial Library, NewJour, Google Scholar

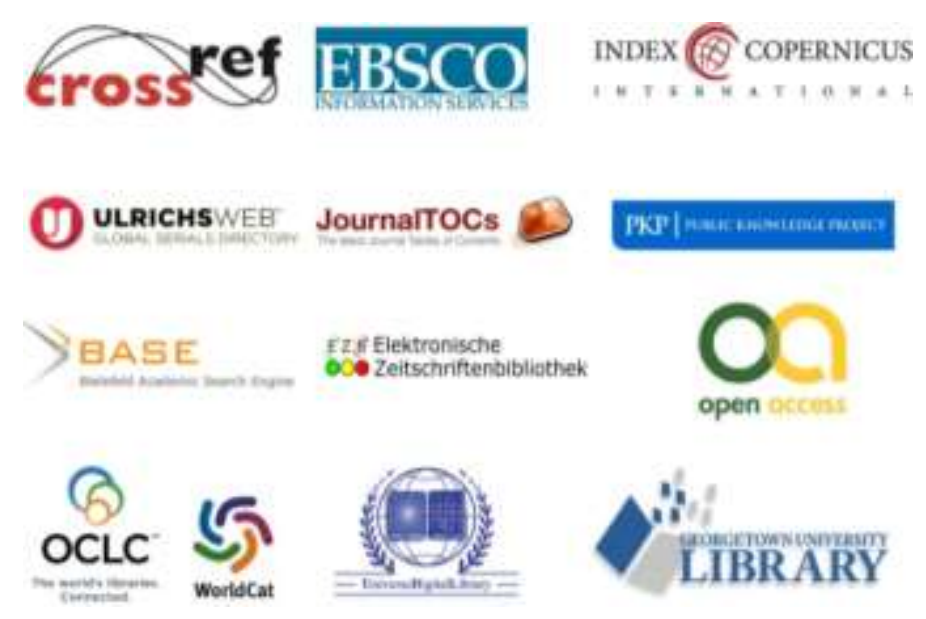

